\title{
Mitochondrial Oxidative Stress after Carbon Monoxide Hypoxia in the Rat Brain
}

\author{
Jing Zhang and Claude A. Piantadosi \\ Department of Medicine, Duke University Medical Center, Durham, North Carolina 27710
}

\begin{abstract}
To better understand the mechanisms of tissue injury during and after carbon monoxide ( $\mathrm{CO}$ ) hypoxia, we studied the generation of partially reduced oxygen species (PROS) in the brains of rats subjected to $1 \% \mathrm{CO}$ for $30 \mathrm{~min}$, and then reoxygenated on air for 0-180 min. By determining $\mathrm{H}_{2} \mathrm{O}_{2}$-dependent inactivation of catalase in the presence of 3-amino-1,2,4-triazole (ATZ), we found increased $\mathrm{H}_{2} \mathrm{O}_{2}$ production in the forebrain after reoxygenation. The localization of catalase to brain microperoxisomes indicated an intracellular site of $\mathrm{H}_{2} \mathrm{O}_{2}$ production; subsequent studies of forebrain mitochondria isolated during and after $\mathrm{CO}$ hypoxia implicated nearby mitochondria as the source of $\mathrm{H}_{2} \mathrm{O}_{2}$. In the mitochondria, two periods of PROS production were indicated by decreases in the ratio of reduced to oxidized glutathione (GSH/GSSG). These periods of oxidative stress occurred immediately after $\mathrm{CO}$ exposure and 120 min after reoxygenation, as indicated by 50 and $43 \%$ decreases in GSH/GSSG, respectively. The glutathione depletion data were supported by studies of hydroxyl radical generation using a salicylate probe. The salicylate hydroxylation products, 2,3 and 2,5-dihydroxybenzoic acid (DHBA), were detected in mitochondria from $\mathrm{CO}$ expoșed rats in significantly increased amounts during the same time intervals as decreases in GSH / GSSG. The DHBA products were increased 3.4-fold immediately after $\mathrm{CO}$ exposure, and threefold after $120 \mathrm{~min}$ reoxygenation. Because these indications of oxidative stress were not prominent in the postmitochondrial fraction, we propose that PROS generated in the brain after $\mathrm{CO}$ hypoxia originate primarily from mitochondria. These PROS may contribute to $\mathrm{CO}$ mediated neuronal damage during reoxygenation after severe CO intoxication. (J. Clin. Invest. 1992. 90:1193-1199.) Key words: oxygen • reactive oxygen species • energy metabolism
\end{abstract}

\section{Introduction}

Carbon monoxide $(\mathrm{CO})$ creates intracellular hypoxia in vivo by tightly binding to hemoglobin, thereby decreasing the $\mathrm{O}_{2}$ carrying capacity of the blood and impairing the release of $\mathrm{O}_{2}$ from hemoglobin (1). Cellular hypoxia, however, does not account for some aspects of $\mathrm{CO}$ toxicity, such as the poor correlation between clinical status and carboxyhemoglobin $(\mathrm{HbCO})^{1}$

Address correspondence to Claude A. Panitadosi, M.D., Associate Professor of Medicine, PO Box 3315, Department of Medicine, Duke University Medical Center, Durham, NC 27710.

Received for publication 6 December 1991 and in revised form 16 March 1992.

J. Clin. Invest.

(C) The American Society for Clinical Investigation, Inc.

0021-9738/92/10/1193/07 \$2.00

Volume 90, October 1992, 1193-1199 level (2) and the remnant effect of $\mathrm{CO}$ after $\mathrm{HbCO}$ has been cleared from the circulation (3). In addition, a delayed central nervous system (CNS) syndrome that cannot be attributed directly to HbCO-mediated hypoxia occurs after serious $\mathrm{CO}$ intoxication in $3-10 \%$ of patients (4). Some recent data indicate that mitochondrial processes contribute to the effects of $\mathrm{CO}$ poisoning in the brain via binding of $\mathrm{CO}$ to reduced cytochrome $c$ oxidase during tissue hypoxia $(5,6)$. This $\mathrm{CO}$ binding impairs the recovery of aerobic energy metabolism in the brain after reoxygenation and is associated with evidence of persistent metabolic acidosis and mitochondrial dysfunction (4-6).

The mechanisms of impaired recovery of energy metabolism after intracellular uptake of $\mathrm{CO}$ by brain mitochondria are probably complex, and there are several potential reasons for continued toxicity during the period of reoxygenation. For example, some data indicating enhanced production of partially reduced oxygen species (PROS) in CO intoxication have been obtained by Thom (7). He has reported lipid peroxidation in the brain after experimental $\mathrm{CO}$ poisoning, suggesting that there may be a reoxygenation injury after $\mathrm{CO}$ hypoxia (7). PROS appear to be important contributors to ischemia-reperfusion injury of a number of tissues including the CNS $(8,9$, $10,11)$. The oxidation of essential proteins, lipids, or nucleic acids by PROS may be critical processes in the pathogenesis of some of these injuries, although most of the precise mechanisms need to be further defined $(11,12,13,14)$.

PROS are generated by the mitochondrial electron transport chain as a byproduct of normal oxidative metabolism, and their production increases when electron transport is inhibited; e.g., with antimycin A (15). Mitochondrial production of superoxide also can be enhanced by increasing the environmental oxygen pressure $(8,15)$. Therefore, we hypothesized that production of PROS was enhanced in brain mitochondria after $\mathrm{CO}$ poisoning when $\mathrm{CO}$ remained bound to cytochrome oxidase and oxygen delivery to the brain increased during reoxygenation (4).

The purposes of this study were to determine if there was oxidative stress involving mitochondria after $\mathrm{CO}$ exposure in the living rat brain, and to study the nature of the PROS involved. Our results demonstrate that mitochondria serve as a source of PROS after $\mathrm{CO}$ poisoning and significant oxidative stress occurs during $\mathrm{CO}$ exposure and 1-2 $\mathrm{h}$ after the onset of reoxygenation. The data implicate hydrogen peroxide $\left(\mathrm{H}_{2} \mathrm{O}_{2}\right)$ and the highly damaging hydroxyl radical $\left(\mathrm{OH}^{\bullet}\right)$ as significant contributors to the intracellular oxidative burden in this model of $\mathrm{CO}$ toxicity.

1. Abbreviations used in this paper: ATZ, 3-amino-1,2,4-triazole; CM, crude mitochondria; DHBA, dehydrobenzoic acid; GSH/GSSG, ratio of reduced to oxidized glutathione; GSSG, acid-soluble oxidized glutathione; $\mathrm{HbCO}$, carboxyhemoglobin; NEM, $\mathrm{N}$-ethylmaleimide; $\mathrm{OH}^{\bullet}$, hydroxyl radical; PMS, postmitochondrial supernatant; PROS, partially reduced oxygen species. 


\section{Methods}

Young male Sprague-Dawley rats (Charles Rivers Breeding Laboratories, Inc., Wilmington, MA) weighing 200-300 g were used in the studies. The production of PROS during and after $\mathrm{CO}$ hypoxia was evaluated in three series of experiments. The first series of experiments assessed $\mathrm{H}_{2} \mathrm{O}_{2}$ generation in different regions of the brain by determining residual catalase activity in the presence of 3-amino-1,2,4-triazole (ATZ). The second series measured changes in reduced and oxidized glutathione in crude mitochondria (CM) and postmitochondrial supernatant (PMS) fractions of the forebrain. The third group of studies was designed to detect hydroxyl radical generation by measuring hydroxylation products of salicylate in forebrain CM and PMS samples.

Animal preparation. The rats were anesthetized with ketamine and diazepam ( 50 and $2.5 \mathrm{mg} / \mathrm{kg}$ i.p., respectively). Tracheal intubation with a $16 \mathrm{G}$ catheter was performed, and the rats were ventilated with a mechanical ventilator (Edco Scientific, Inc., Chapel Hill, NC). Polyethylene catheters were placed in a femoral artery and vein for blood pressure monitoring and additional drug administration. A thermostatically controlled heating pad beneath the rat maintained rectal temperature near $37^{\circ} \mathrm{C}$. Arterial blood samples were drawn intermittently for measurement of arterial $\mathrm{PO}_{2}, \mathrm{PCO}_{2}$, and $\mathrm{pH}\left(\mathrm{PaCO}_{2}, \mathrm{PaCO}_{2}\right.$, and $\left.\mathrm{pHa}\right)$ (model 813 pH/blood gas analyzer; Instrumentation Laboratory, Inc., Lexington, MA). Respiratory rate and/or tidal volume were adjusted to maintain $\mathrm{PaCO}_{2}$ at 35-45 Torr. Additional aliquots of arterial blood $(200 \mu \mathrm{l})$ were used to measure total hemoglobin in grams per $100 \mathrm{ml}$ blood; percentage of oxyhemoglobin $\left(\mathrm{HbO}_{2}\right)$, percentage of $\mathrm{HbCO}$, deoxyhemoglobin, methemoglobin; and arterial $\mathrm{O}_{2}$ content $\left(\mathrm{CaO}_{2}\right)$ (model 482 CO-oximeter; Instrumentation Laboratory Inc., Lexington, MA). A total of three $0.75-\mathrm{ml}$ aliquots of blood were removed for these analyses. Approximately $2 \mathrm{ml}$ of normal saline was infused intravenously after removal of each blood sample. $\mathrm{CO}$ exposures were performed with a premixed gas containing $1 \% \mathrm{CO}$ and $90 \% \mathrm{O}_{2}$ balance $\mathrm{N}_{2}$. This gas mixture was chosen because it has been demonstrated to lead to sublethal uptake of $\mathrm{CO}$ by cytochrome oxidase in the rat brain (6).

In several separate experiments, blood flow in the carotid artery was measured during and after $\mathrm{CO}$ hypoxia to demonstrate that the exposures were nonischemic. For these studies, the preparative procedures were identical, except that one common carotid artery was isolated and a $2.5-\mathrm{mm}$ diameter electromagnetic flow probe placed around it. The pulsatile flow in the vessel was recorded continuously with a flowmeter (model FM501; CME, King, NC) connected to a strip chart recorder (model 481; Gould Inc., Glen Burnie, MD).

Determination of $\mathrm{H}_{2} \mathrm{O}_{2}$ production. Residual catalase activity was measured in six brain regions $30 \mathrm{~min}$ after the administration of the $\mathrm{H}_{2} \mathrm{O}_{2}$-dependent inhibitor of catalase (ATZ), as previously described (16). 36 rats were divided into six groups: $1 \mathrm{~A}$, control (ventilated with air for $30 \mathrm{~min}$ ); $2 \mathrm{~A}, 30 \mathrm{~min} \mathrm{CO}$ (exposure to $1 \% \mathrm{CO}$ for $30 \mathrm{~min}$ ); $3 \mathrm{~A}$, $30 \mathrm{~min} \mathrm{CO}+30 \mathrm{~min}$ air ; $4 \mathrm{~A}, 30 \mathrm{~min} \mathrm{CO}+60 \mathrm{~min}$ air; $5 \mathrm{~A}, 30 \mathrm{~min} \mathrm{CO}$ $+120 \mathrm{~min}$ air; and $6 \mathrm{~A}, 30 \mathrm{~min} \mathrm{CO}+180 \mathrm{~min}$ air. All animals received $1 \mathrm{~g} \mathrm{~kg}^{-1}$ ATZ i.p. 30 min before the end of the experiments. At the designated times, the brains were perfused free of blood with cold normal saline via one carotid artery. The cold brain was rapidly dissected into six regions: $(a)$ anterior cortex and subcortex; $(b)$ right posterior cortex; $(c)$ left posterior cortex; $(d)$ cerebellum; $(e)$ medulla-pons; and $(f)$ posterior subcortex. The posterior cortex was separated from the subcortex by cutting into the corpus callosum and dissecting the caudate, putamen, and Ammon's horn from the anterior cingulate cortex and parieto-occipital cortex. The samples were minced and homogenized in potassium phosphate buffer at $\mathrm{pH} 7.0(16,17)$. The catalase activity in the brain samples was measured in an oxygraph at $25^{\circ} \mathrm{C}$ using $25 \mathrm{mM} \mathrm{H}_{2} \mathrm{O}_{2}$ as the substrate. This assay is the polarographic method of Del Rio et al. with minor modifications (18). Specific catalase activity in the brain was expressed as $\mu \mathrm{mol} \mathrm{O}_{2}$ evolved $\min ^{-1} \mu \mathrm{g}$ $\mathrm{DNA}^{-1}$. DNA concentration in each brain region was determined fluorometrically using the bisbenzimide reaction (model 112 fluorometer; Turner Designs, Mountain View, CA) (19). Brains containing $<60 \mu \mathrm{g} \mathrm{ATZ} / \mathrm{g}$ wet $\mathrm{wt}$, measured colorimetrically from a diazotized
ATZ derivative, were not used to be certain that ATZ concentration would not be rate limiting for catalase inhibition in the presence of $\mathrm{H}_{2} \mathrm{O}_{2}(20)$. Three animals did not meet the ATZ criterion for the study, however, three other rats that met the ATZ criterion were added to complete the study.

Isolation of forebrain mitochondria. After the studies of $\mathrm{H}_{2} \mathrm{O}_{2}$ production were completed, additional studies of PROS generation were conducted on crude brain mitochondria and postmitochondrial supernatant. At the appropriate times, the brains were perfused rapidly and removed en bloc. The forebrain was separated from the cerebellum and medulla-pons, and CM and PMS were prepared from each forebrain by the method of Clark and Nicklas (21). The isolation medium contained $0.225 \mathrm{M}$ mannitol, $0.075 \mathrm{M}$ sucrose, $1.0 \mathrm{mM}$ EDTA, and $0.2 \%$ BSA. This procedure yields well-coupled neuronal mitochondria of both free and synaptosomal origin (22).

To estimate the yield of CM from a single rat brain, cytochrome $c$ oxidase activity was measured polarographically in CM, PMS, and whole brain homogenate fractions. The extent of subcellular fractionation also was quantified spectrophotometrically in three control experiments by determining the ratio of cytochrome $c$ oxidase activities in the CM and PMS fractions using ferrocytochrome $c$ oxidation at 550 $\mathrm{nm}$ (23). Specific mitochondrial enzyme activity was measured in both fractions from the linear region of the activity curve using a spectrophotometer (model U-2000; Hitachi Science Instr., Mountain View, CA ) and was expressed as units mg protein ${ }^{-1}$. Standard curves were constructed using known concentrations of the enzyme. The Biuret reaction was used for protein determinations (24).

Measurements of reduced and oxidized glutathione. 36 rats were divided into six groups ( $1 \mathrm{~B}-6 \mathrm{~B}$ ), and were subjected to the some exposure conditions used for the catalase experiments. Acid-soluble oxidized glutathione (GSSG) and total glutathione (GSH + GSSG) were measured spectrophotometrically at $412 \mathrm{~nm}$ by a recycling method with 5,5'-dithiobis (2-nitrobenzoic acid) (DTNB) (25). During the GSSG assay, $N$-ethylmaleimide (NEM) was added to all samples to prevent spontaneous oxidation of GSH to GSSG in vitro. NEM was then removed by chromatographic separation through a C18 SepPak column (Waters Chromatography Division, Milford, MA), since it interferes with the assay (26). After passing the samples through the SepPak and subsequent washing, GSSG concentrations were very low in the control brain samples; therefore, $2 \mathrm{nmol}$ of GSSG was added to all samples to improve the detection of GSSG in the control samples.

Determination of hydroxylation products of salicylate. In vitro, the attack of $\mathrm{OH}^{\bullet}$ on salicylic acid (2-hydroxybenzoic acid) produces two dihydroxybenzoic acid products, 2,3- and 2,5-dihydroxybenzoic acid (2,3-DHBA and 2,5-DHBA), and a small amount of catechol by decarboxylation ( 8 ). These nonnatural hydroxylated products, specifically 2,3-DHBA, have been used in vivo to detect hydroxyl radical generation in several previous studies $(27,28)$. The detection of 2,3-DHBA and 2,5-DHBA was performed using high performance liquid chromatography with electrochemical detection, as described by Floyd (27). Rats were subjected to the same conditions as for the glutathione measurements, except that sodium salicylate was injected $\left(100 \mathrm{mg} \mathrm{kg}^{-1}\right.$ i.p.) $60 \mathrm{~min}$ before perfusing the brain. This dose produced salicylate concentrations in the brain in the range of 5-10 $\mu \mathrm{M}$ detectable in both CM and PMS for 45-90 min after the injection. CM and PMS fractions were isolated as described above. The protein in both fractions was precipitated with $10 \%$ TCA (final concentration) and the supernatant was then centrifuged (Microfuge E; Beckman Instr., Inc., Fullerton, CA) through a $0.22 \mu \mathrm{m}$ microfuge tube filter (model 352-118; PGC Scientific, Gaithersburg, MD) at $15,000 \mathrm{~g}$. A $100 \mu \mathrm{l}$ sample of the eluate was injected onto a C18 RP HPLC column $(250 \times 4.6 \mathrm{~mm}$, model 235329; Beckman). DHBAs were quantified with a Coulochem electrochemical detector (model 5100A; ESA, Inc., Bedford, MA) with the detector set at a reducing potential of -0.40 volts $D C$. The guard cell (used as a screen) was set at an oxidizing potential of +0.40 volts DC (29). Preliminary experiments determined that these settings provided sensitive detection of the DHBA products with minimal interference from other compounds in the brain samples. The peak height was 


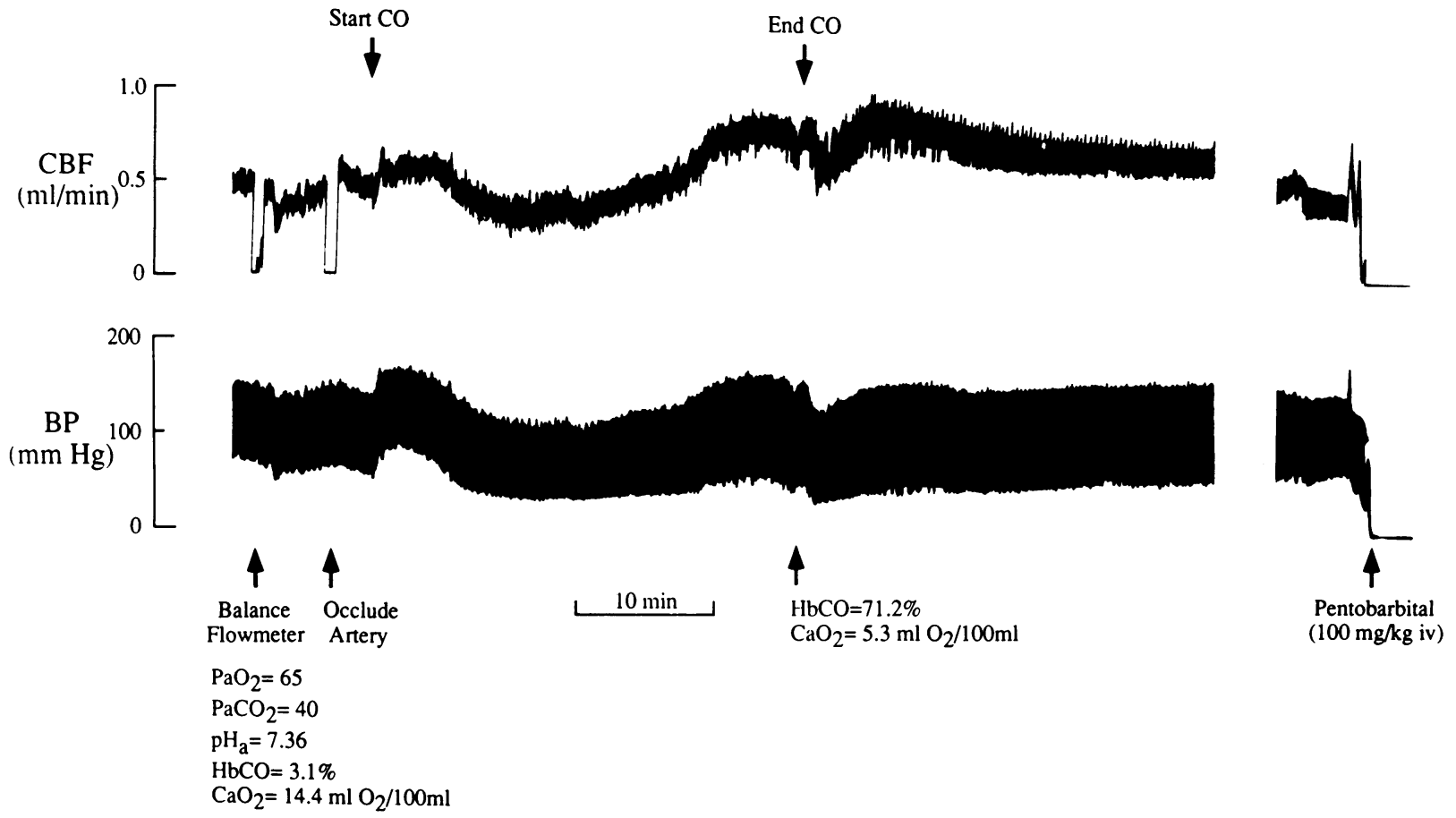

Figure 1. Blood flow in the carotid artery. Carotid blood flow increased soon after CO exposure began and remained elevated for $\sim 60$ min after the end of the $\mathrm{CO}$ exposure. Pentobarbital administered $60 \mathrm{~min}$ after the end of the exposure.

measured using a standard linear baseline correction method and compared to values obtained using authentic standards added to the samples. The sensitivity of the method was $\sim 600 \mathrm{fmol}$ of DHBA per ml of brain extract. Salicylic acid was monitored with fluorometer through a quartz flow cell at an excitation wavelength of $300 \mathrm{~nm}$ and an emission wavelength of $412 \mathrm{~nm}$ (model FD-300; Groton Technical, Inc., Concord, MA).

Chemicals. $\mathrm{H}_{2} \mathrm{O}_{2}(30 \%$ vol/vol ) was obtained from Sigma Chemical Co. (St. Louis, MO). The concentration was verified by its absorbance at $240 \mathrm{~nm}$ (18). Triton X-100, ATZ, single stranded calf thymus DNA, bisbenzimide, sodium nitrite, NEM, GSSG, glutathione reductase, NADPH, DTNB, salicylate, 2,3-DHBA, 2,5-DHBA, catalase, cytochrome $c$, cytochrome $c$ oxidase, succinate, rotenone, and 2,4-dinitrophenol also were purchased from Sigma.

Statistical methods. Grouped data were expressed as means \pm SE. All data were entered into a computer spreadsheet for statistical analysis. Changes in specific catalase activity, GSH/GSSG, and DHBA concentration were analyzed by one-way ANOVA. $P<0.05$ was accepted as significant.

\section{Results}

The rats exposed to $\mathrm{CO}$ for $30 \mathrm{~min}$ in this study showed an increase in arterial $\mathrm{HbCO}$ level from $3.4+0.1 \%$ to $70.0 \pm 1.2 \%$. Carotid blood flow increased during $\mathrm{CO}$ exposure, and remained elevated for $\sim 1 \mathrm{~h}$ after the end of the $\mathrm{CO}$ exposures (Fig. 1), which indicated that autoregulatory mechanisms were able to provide additional blood flow to the brain during and after CO hypoxia. A summary of the characteristic changes in other pertinent physiologic variables measured over time are presented in Table I. Of note, arterial $\mathrm{O}_{2}$ content fell from $18.0 \pm 0.8$ to $5.1 \pm 0.1$ during $\mathrm{CO}$ exposure, indicating profound tissue hypoxia despite the $\mathrm{O}_{2}$ present in the breathing gas during the $\mathrm{CO}$ exposure. Mean arterial pressure (MAP) decreased soon after $\mathrm{CO}$ exposure began and recovered nearly to baseline after reoxygenation on air for $180 \mathrm{~min}$. The $\mathrm{pHa}$ and $\mathrm{PaCO}_{2}$ fluctuated somewhat, but these changes were not significant.

Table I. General Physiological Variables

\begin{tabular}{|c|c|c|c|c|c|c|}
\hline & \multicolumn{6}{|c|}{ Time after $1 \% \mathrm{CO}-90 \% \mathrm{O}_{2}$ Exposure (min) } \\
\hline & Control & 0 & 30 & 60 & 120 & 180 \\
\hline $\mathrm{MAP}, \mathrm{mmHg}$ & $118 \pm 7$ & $45 \pm 2 *$ & $60 \pm 2^{*}$ & $82 \pm 2 *$ & $90 \pm 2 *$ & $95 \pm 3^{*}$ \\
\hline $\mathrm{HbCO}, \%$ & $3.4 \pm 0.1$ & $70 \pm 1.2^{*}$ & $30.4 \pm 2.2^{*}$ & $28.9 \pm 3.8^{*}$ & $11.0 \pm 0.8^{*}$ & $7.7 \pm 0.7^{*}$ \\
\hline $\mathrm{CaO}_{2}$, vol $\%$ & $18.0 \pm 0.8$ & $5.1 \pm 0.1^{*}$ & $11.3 \pm 0.6^{*}$ & $12.0 \pm 0.5^{*}$ & $15.1 \pm 0.5^{*}$ & $16.5 \pm 0.6$ \\
\hline $\mathrm{PaCO}_{2}, \mathrm{mmHg}$ & $37.1 \pm 2.4$ & $35.3 \pm 1.2$ & $33.1 \pm 0.9$ & $39.7 \pm 3.3$ & $33.7 \pm 1.9$ & $36.5 \pm 2.9$ \\
\hline $\mathrm{PaO}_{2}, \mathrm{mmHg}$ & $81.8 \pm 4.4$ & $242.9 \pm 9.4^{*}$ & $84.6 \pm 4.1$ & $73.7 \pm 4.0$ & $82.7 \pm 2.2$ & $91.0 \pm 6.0$ \\
\hline $\mathrm{pHa}$ & $7.42 \pm 0.01$ & $7.36 \pm 0.04$ & $7.36 \pm 0.02$ & $7.37 \pm 0.02$ & $7.40 \pm 0.02$ & $7.38 \pm .04$ \\
\hline Temp, ${ }^{\circ} \mathrm{C}$ & $37.2 \pm 0.2$ & $37.2 \pm 0.1$ & $37.0 \pm 0.3$ & $37.0 \pm 0.3$ & $37.1 \pm 0.2$ & $37.1 \pm 0.1$ \\
\hline
\end{tabular}

Values are means $\pm \mathrm{SE}$ ( $n=6$ in each group). MAP, mean arterial pressure; $\mathrm{HbCO}$, carboxyhemoglobin; $\mathrm{CaO}_{2}$, arterial $\mathrm{O}_{2}$ content; $\mathrm{Pa}_{\mathrm{co}_{2}}, \mathrm{~Pa}_{\mathrm{o}_{2}}$, pHa, arterial $\mathrm{PCO}_{2}, \mathrm{Po}_{2}, \mathrm{pH}$. ${ }^{*} P<0.05$ compared with control. 
The other parameters returned to control levels within $180 \mathrm{~min}$ of the onset of reoxygenation.

$\mathrm{H}_{2} \mathrm{O}_{2}$ generation. $\mathrm{H}_{2} \mathrm{O}_{2}$ production in the brain was assessed ex vivo by the disappearance of catalase activity from brain samples in the presence of its $\mathrm{H}_{2} \mathrm{O}_{2}$ dependent, irreversible inhibitor, ATZ. Regional catalase activities in the six control brain regions were expressed as $\mu \mathrm{mol} \mathrm{O}_{2} \mathrm{~min}^{-1}, \mu \mathrm{g}$ ssDNA $^{-1}$. These values were $(a) 0.037 \pm 0.002 ;$ (b) 0.033 \pm 0.003 ; (c) $0.031 \pm 0.002$; (d) 0.022 \pm 0.003 ; (e) 0.053 \pm 0.005 ; and $(f) 0.041 \pm 0.002$. Changes in specific catalase activity after ATZ administration in CO exposed animals (groups 2A-6A) relative to control are shown in Fig. 2 for all six brain regions. Decreases in residual catalase activity occurred in four regions: anterior cortex and subcortex, right posterior cortex, left posterior cortex, and posterior subcortex at 60-120 min after reoxygenation. Statistical significance was reached in two of the six brain regions, the anterior cortex and subcortex, and the posterior subcortex. These decreases in catalase activity indicated an increase in the formation of ATZ- $\mathrm{H}_{2} \mathrm{O}_{2}$-catalase complex relative to control studies. At non-rate limiting ATZ concentrations, formation of the complex is pseudo-first order with respect to time and $\mathrm{H}_{2} \mathrm{O}_{2}$ concentration $(16,20)$. Because ATZ was given $30 \mathrm{~min}$ before brain harvesting in all animals, the decreases in regional catalase activity were proportional to the rate of $\mathrm{H}_{2} \mathrm{O}_{2}$ reaching the microperoxisome during the $30 \mathrm{~min}$ periods of $\mathrm{CO}$ hypoxia and reoxygenation. Since $\mathrm{H}_{2} \mathrm{O}_{2}$ generation was not pronounced in cerebellum and medulla-pons during or after $\mathrm{CO}$ exposure, we concentrated on subcellular fractions of the forebrain for subsequent analyses of GSH/GSSG and salicylate hydroxylation products.

Assay of cytochrome oxidase activity. Functional cy-

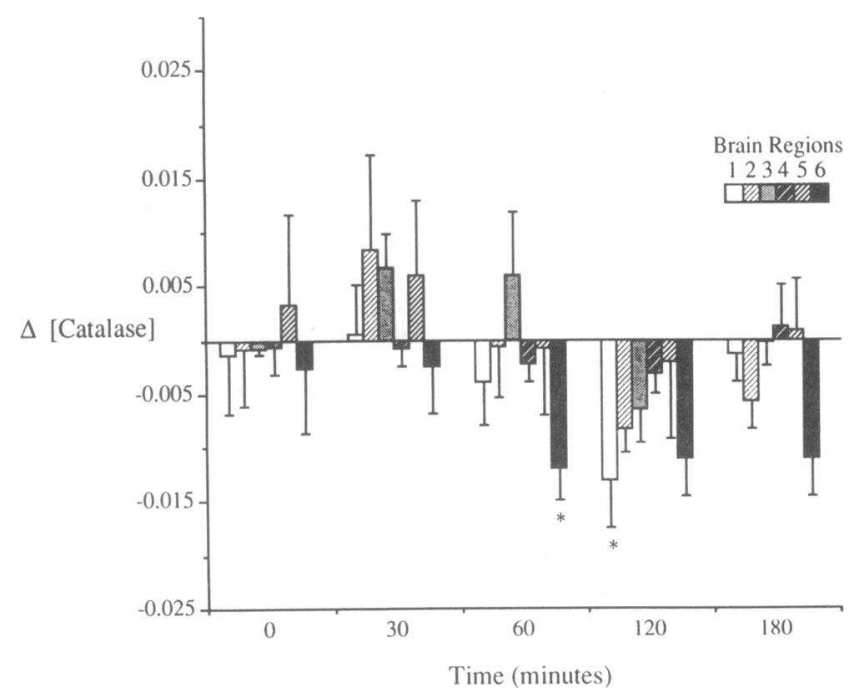

Figure 2. Catalase activity in six regions of the rat brain after $\mathrm{CO}$ poisoning with the presence of ATZ (2A-6A). Values were subtracted from enzyme activity values in $30 \mathrm{~min}$ air control (1A). Catalase activity expressed as $\mu \mathrm{mol} \mathrm{O}_{2}$ evolve $\min ^{-1} \mu \mathrm{g} \mathrm{ssDNA}^{-1}(n=6$ in all six groups). The six brain regions were (1) anterior cortex and subcortex (white bar); (2) right posterior cortex (light striped bar); (3) left posterior cortex (dotted bar); (4) cerebellum (dark striped bar); (5) medulla pons (moderate striped bar); and (6) posterior subcortex (black bar), respectively. Stars beneath each bars indicate that enzyme activities in these regions were significantly lower than the control values. tochrome $c$ oxidase is found only in mitochondria, thus the presence of the oxidase activity in the PMS indicates the degree of contamination by mitochondria after the fractionation procedures. In this study, the $\mathrm{O}_{2}$ consumption of the PMS fraction in the oxygraph in three experiments was near zero after adding succinate, rotenone, and 2,4-dinitrophenol to the samples. The $\mathrm{CM}$ samples, however, consumed $\mathrm{O}_{2}$ at a rate of approximately one fifth of the maximum $\mathrm{O}_{2}$ consumption of fresh whole brain homogenate under the same conditions (data not shown). In three additional experiments, the cytochrome oxidase activity measured by the addition of reduced cytochrome $c$ to isolated cellular fractions indicated that the ratio of specific enzyme activity of CM/PMS was $>10$, indicating adequate separation of the CM from the PMS compartment.

Glutathione measurements. To localize potential sources of $\mathrm{H}_{2} \mathrm{O}_{2}$ generation within the cell, GSSG and GSH were measured in both CM and PMS fractions. In control samples, the values of GSH were $11.9 \pm 0.46$ in $C M$ and $60.7 \pm 2.9$ in PMS $\left(\mathrm{nmol} \mathrm{mg}\right.$ protein $\left.{ }^{-1}\right)$. Mean GSSG values were $0.12 \pm 0.01$ in $\mathrm{CM}$ and $0.62 \pm 0.07$ in PMS, respectively $\left(\mathrm{nmol} \mathrm{mg} \mathrm{protein}{ }^{-1}\right.$ ). The ratios of GSH to GSSG in both cellular fractions are presented in Fig. 3. Overall, the GSH/GSSG did not change significantly in the PMS fraction, although there was a small decrease in the ratio $180 \mathrm{~min}$ after reoxygenation. In contrast, the CM compartment showed significant declines in the GSH/GSSG ratio at two time points, immediately after the end of $30 \mathrm{~min}$ of $\mathrm{CO}$ exposure and after $120 \mathrm{~min}$ of reoxygenation. These declines in the GSH/GSSG ratio were attributed to the combination of a decrease in GSH and an increase in the GSSG values. These data suggest that PROS were produced during $\mathrm{CO}$ poisoning and after reoxygenation within the mitochondria. The oxidative stress in the reoxygenation phase appeared to be greater than during the period of $\mathrm{CO}$ poisoning because catalase activity in the microperoxisome was decreased only after reoxygenation. A non-peroxide-dependent effect on the GSH, GSSG ratio, however, could not be excluded entirely, since $\mathrm{CO}$ could have impaired GSH-GSSG related enzymes directly or indirectly through tissue hypoxia and/or change in tissue $\mathrm{pH}$. As a result, further studies were conducted to determine if hy-

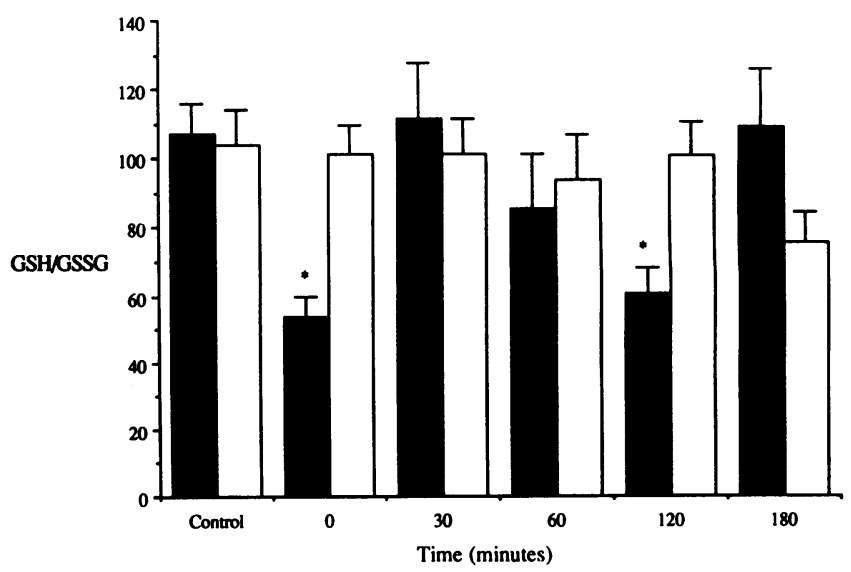

Figure 3. GSH/GSSG in both CM and PMS compartments after CO exposure (1B-6B). Values are means \pm SE for $n=6$ in all groups. Overall, there was no significant change in the values for the PMS fraction throughout the experiments. The $\mathrm{CM}$ compartment, however, demonstrated two declining phases in the ratio, right after $\mathrm{CO}$ poisoning and after $120 \mathrm{~min}$ reperfusion. $\mathrm{\Perp}, \mathrm{CM}$;, PMS. 
droxyl radical could be detected after $\mathrm{CO}$ hypoxia, and if so, its relationship to the time course of the $\mathrm{H}_{2} \mathrm{O}_{2}$ generation.

Hydroxyl radical generation. The generation of hydroxyl radical was assessed in both CM and PMS fractions by monitoring salicylate hydroxylation products. The possibility of postmortem salicylate hydroxylation was examined by measuring DHBAs in both CM and PMS of forebrain of three control rats to which salicylate $\left(100 \mathrm{mg} \mathrm{kg}^{-1}\right)$ was given during perfusion of the carotid artery at the time the brain was removed. These data indicated that $55 \%$ in CM and $74 \%$ in PMS of the total concentrations of DHBA detected in the control study were generated postmortem.

Representative chromatograms of rat brain mitochondria are presented in Fig. 4, showing the production of 2,5 and 2,3-DHBA $60 \mathrm{~min}$ after $\mathrm{CO}$ hypoxia. The measured amounts of each DHBA product after CO exposure in each of the two compartments are shown in Figs. 5 (CM) and 6 (PMS), respectively. The concentration of 2,3-DHBA in the CM compartment significantly increased immediately after $\mathrm{CO}$ exposure, and $30 \mathrm{~min}$ and $120 \mathrm{~min}$ after recovery on air. The 2,5-DHBA in $\mathrm{CM}$ also was elevated significantly after $\mathrm{CO}$ exposure and $120 \mathrm{~min}$ after the recovery (Fig. $5 \mathrm{~A}$ ). The total amount of hydroxylation product detected for the $\mathrm{CM}$ fraction (sum of 2,3-DHBA plus 2,5-DHBA) is presented in Fig. $5 \mathrm{~B}$. The pattern of changes was closely similar to the GSH/GSSG results shown in Fig. 3. The hydroxyl data for the PMS fraction suggested that significant hydroxyl radical production did not occur in that compartment after $\mathrm{CO}$ exposure (Fig. $6 \mathrm{~B}$ ). The 2,3-DHBA levels in PMS increased significantly after CO exposure and after $120 \mathrm{~min}$ reoxygenation (Fig. $6 \mathrm{~A}$ ); however, there was little increase in the amount of 2,5-DHBA generated after $\mathrm{CO}$ hypoxia (Fig. $6 \mathrm{~A}$ ). The small 2,3-DHBA increase in the PMS may indicate DHBA leakage from the mitochondria. The actual ratio of DHBA concentrations for PMS: CM was considerably lower than the values presented in Figs. 5 and 6, since only about one fifth of the mitochondria were recovered from the brain. In fact, local DHBA concentration in the CM were probably higher than in the PMS, since mitochondria only account for $10 \%$ of total cell volume.

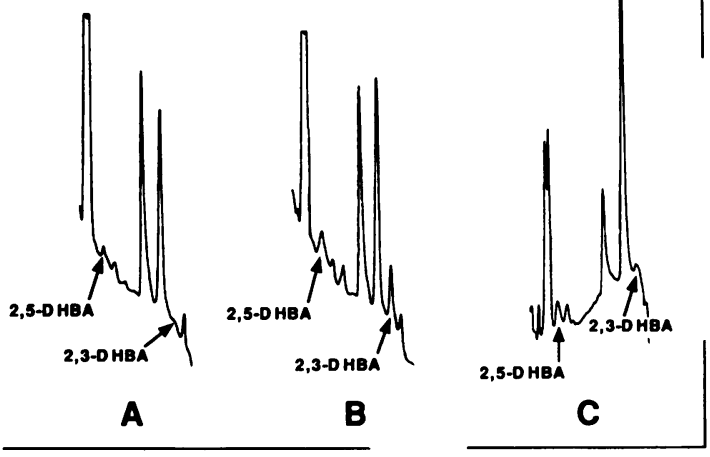

Figure 4. Representative chromatograms of salicylate hydroxyglation products (DHBA). $(A)$ Crude mitochondria isolated from rat brain treated with salicylate under control conditions. $(B)$ Repeat of the same sample as $(A)$ except that 2 pmol of each 2,3- \& 2,5 DHBA was added. $(C)$ Crude mitochondria obtained from rat brain 60 min after $\mathrm{CO}$ exposure and reoxygenation.

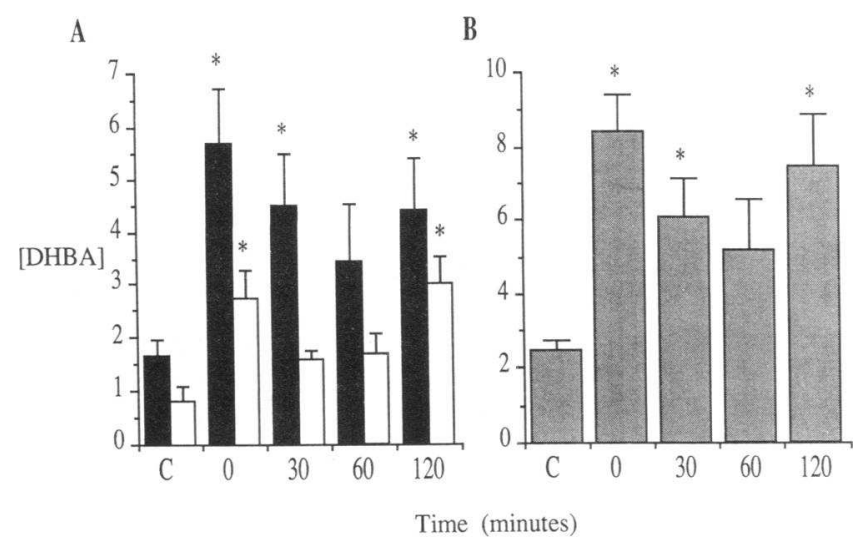

Figure 5. Generation of hydroxyl radical in $\mathrm{CM}$ after $\mathrm{CO}$ exposure. Values are means \pm SE for $n=4$ in all five groups expressed as pmol $\mathrm{g}$ brain $^{-1}$. Values of 2,3-DHBA and 2,5-DHBA are depicted separately in $(A)$; total DHBA are presented in $(B)$. Two phases of increased DHBA were detected (i.e., right after $C O$ exposure and after 120 min reperfusion). The stars indicate values that are significantly

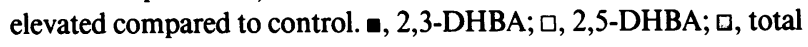
DHBA.

\section{Discussion}

The data presented in this study provide the first clear evidence of substantial oxidative stress in during $\mathrm{CO}$ poisoning and after reoxygenation of the brain in pathologically vulnerable brain regions and at the mitochondria. These new findings offer a possible explanation for some of the delayed toxicity of $\mathrm{CO}$ poisoning on the brain. The putative mechanism involves generation of PROS in excess of the capacity of local antioxidant defenses to deal with them; this leads to mitochondrial damage by oxidation of essential enzymes, lipids, or mitochondrial DNA $(8,14)$. If severe enough, these effects could contribute to late energy failure by mitochondria and subsequently to neuronal death.

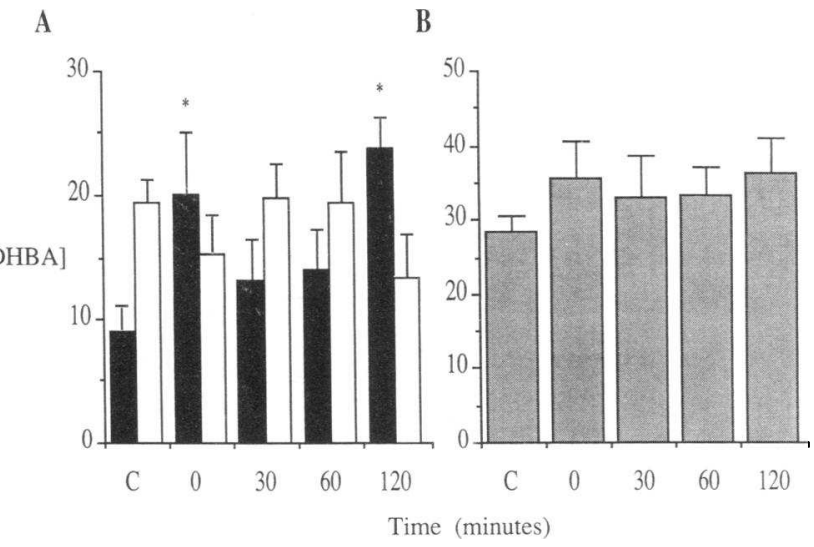

Figure 6. Generation of hydroxyl radical in PMS after $\mathrm{CO}$ exposure. Values are means \pm SE for $n=4$ in all five groups expressed as pmol $\mathrm{g}$ brain $^{-1}$. The 2,3-DHBA and 2,5-DHBA are shown separately in $(A)$, while total DHBA are presented in $(B)$. No significant change was observed in total hydroxyl radical, although some increase in 2,3-DHBA was detected in PMS. $₫$, 2,3-DHBA; $\square, 2,5-\mathrm{DHBA}$; $\square$, total DHBA. 
Regional generation of $\mathrm{H}_{2} \mathrm{O}_{2}$ detected by means of inactivation of catalase by ATZ (Fig. 2) indicated that the subcortical regions, which include the basal ganglia, may be a major source of PROS after CO exposure. This region is also known to be highly vulnerable to neuropathological injury from $\mathrm{CO}$ intoxication (4). The increase in PROS at the microperoxisome, however, did not coincide with the GSH/GSSG data in the PMS fraction because the GSH/GSSG did not decrease in the PMS. There are several straightforward interpretations of these results. First, the microperoxisomes, where catalase is localized, surround neuronal mitochondria in the brain forming balloonlike structures (8). Therefore, any $\mathrm{H}_{2} \mathrm{O}_{2}$ diffusing out of mitochondria could be converted to $\mathrm{H}_{2} \mathrm{O}_{2}$ and $\mathrm{O}_{2}$ in the microperoxisomes without affecting the cytosolic GSH system. Second, the lack of a GSSG increase in PMS may simply reflect diffusion or export of GSSG out of the cell. This possibility could be verified in future studies by measuring blood and CSF levels of GSSG. Finally, the failure to detect a change in GSSG in the PMS also may be related to the ease with which GSSG can be recycled to GSH through GSSG reductase. Again, a GSSG reductase blocker could be used to test this hypothesis. The more interesting and relevant study, however, would require technically demanding measurements of GSH/GSSG and DHBAs in the organelles in different brain regions to determine if regions most vulnerable to $\mathrm{CO}$-mediated damage show similar evidence of oxidative stress.

The increase in mitochondrial GSSG detected in our study is potentially quite deleterious in itself because of the inability of mitochondria to export GSSG (30). GSSG per se is capable of oxidizing proteins, and thereby could be deleterious to mitochondrial function (31). The elevated GSH/GSSG in the mitochondrial fraction correlated well with DHBA levels; i.e., both sets of experiments indicated at least two periods of oxidant production, immediately after $\mathrm{CO}$ exposure and after 120 min reoxygenation. The DHBA concentrations in control samples were higher in PMS than CM, however, the DHBA values in CM reflected only one fifth of the total mass of brain mitochondria. Finally, the high 2,5-DHBA relative to 2,3-DHBA levels in the control PMS fraction may have originated from enzymatic activity of cytochrome P-450 as indicated in other studies $(28,32)$, although mixed function oxidase activity in the brain is quite low (33).

In this study, the GSSG and DHBA results clearly implicate mitochondria as a major source of PROS generation in $\mathrm{CO}$ toxicity. The time course of the GSH/GSSG and DHBAs generation agree well with our earlier observation that $\mathrm{CO}$ binds to cytochrome $c$ oxidase in vivo for a prolonged period after reoxygenation (6). CO thus inhibits mitochondrial electron transport and enhances the possibility of electron leakage from the carriers; e.g., ubquinone-cytochrome $b$-c $c_{1}$ region of the respiratory chain. Under these circumstances, superoxide anion can be generated and converted by manganese superoxide dismutase to $\mathrm{H}_{2} \mathrm{O}_{2}(8,15,34)$. It also has been documented that favorable conditions for Fenton reactions exist in tissues regions rich in transition metals such as iron. This iron can be mobilized in certain pathologic situations such as acidosis. Interestingly, in the brain, both iron-rich regions (e.g., basal ganglia [8]), and persistent acidosis after CO poisoning (6) have been reported. Therefore, it is reasonable to hypothesize that PROS (e.g., superoxide and $\mathrm{H}_{2} \mathrm{O}_{2}$ ) are generated from the mitochondrial electron transport chain by $\mathrm{CO}$ binding to the terminal oxidase. These PROS, in the presence of acidosis and active iron, could lead to hydroxyl radical production. The data do not exclude the possibility, however, that other sources of $\mathrm{O}_{2}$ radical generation not related to inhibition of electron transport contributed to the findings.

The oxidative stress reported herein during the actual period of $\mathrm{CO}$ poisoning was somewhat unexpected considering the extent of tissue hypoxia expected to accompany a severe restriction in cerebral oxygen delivery (35). Of note, the second period of PROS production appeared to exceed the first because catalase inactivation by ATZ increased only after reoxygenation. These findings differ from a previous $\mathrm{CO}$ report, where an increase in lipid peroxidation was detected only after reoxygenation (7). The decrease in GSH/GSSG during CO exposure could indicate an oxidative stress that did not overcome antioxidant defenses to initiate lipid peroxidation, however, the hydroxyl radical data strongly suggest that oxidant damage to mitochondria occurs during the period of $\mathrm{CO}$ exposure. During and after $\mathrm{CO}$ hypoxia, highly reactive hydroxyl radicals generated from $\mathrm{H}_{2} \mathrm{O}_{2}$ in the presence of iron and a source of electrons (e.g., superoxide) will damage virtually any of molecule found in living cells. These reactions can lead to extensive and irreversible cellular changes $(14,36)$.

The compartmental glutathione and DHBA assays employed in this study are likely to be more sensitive than whole brain measurements; e.g., determination of conjugated diene formation in whole brain (7). Mitochondrial GSH, for instance, only accounts for $10-15 \%$ of total cell pool size of GSH (31), so that an important mitochondrial oxidative stress could be missed easily by global measurements of GSH or lipid peroxidation. Also, the prominent increases in oxidative stress were detected only in mitochondria and not cytosol. This finding diminished potential concerns that some of the changes might be attributable to contamination from blood components; e.g., white cells. Further investigations at the subcellular level are needed, however, to relate precisely the effects of oxidant production to mitochondrial dysfunction during $\mathrm{CO}$ toxicity.

In conclusion, acute $\mathrm{CO}$ intoxication generated oxidative stress in the brain of the rat that reached a maximum after 60-120 min of reoxygenation and was primarily attributable to the increased generation of PROS at the mitochondrial level. These data suggest that significant $\mathrm{CO}$-mediated neuronal damage is caused by the deleterious effects of these PROS on mitochondrial function after the exposure. Our findings should point the way to novel investigations of specific mechanisms of oxidative mitochondrial damage that may provide insight into the poorly understood late neurological sequelae of $\mathrm{CO}$ toxicity.

\section{Acknowledgments}

This work was supported by National Institutes of Health grant P01HL42444-02 and by funds from the Veterans' Administration. The authors thank Lynn Tatro and Craig Marshall for excellent technical help and Louise Wilson for preparation of the manuscript.

\section{References}

1. Coburn, R. F., and H. J. Forman. 1987. Carbon monoxide toxicity. In Handbook of Physiology, Section 3: The Respiratory System, Vol. 4. Gas exchange. L. E. Farhi, and S. M. Tenney, editors. American Physiological Society, Bethesda, MD. 439-456.

2. Savolainen, H., K. Kurppa, R. Tenhunen, and H. Kivisto. 1980. Biochemical effects of carbon monoxide poisoning in rat brain with special reference to 
blood carboxyhemoglobin and cerebral cytochrome oxidase activity. Neurosci. Lett. 19:319-323.

3. Halperin, M. H., R. A. McFarland, J. I. Niven, and F. J. W. Roughton. 1959. The time course of the effects of carbon monoxide on visual thresholds. $J$. Physiol. (Camb.). 146:583-593.

4. Piantadosi, C. A. 1990. Carbon monoxide intoxication. In Update in Intensive Care and Emergency Medicine. J. L. Vincent, editor. Springer-Verlag Inc., New York, New York. 460-471.

5. Brown, S. D., and C. A. Piantadosi. 1990. In vivo binding of carbon monoxide to cytochrome $c$ oxidase in rat brain. J. Appl. Physiol. 68:604-610.

6. Brown, S. D., and C. A. Piantadosi. 1991. Recovery of energy metabolism in rat brain after carbon monoxide hypoxia. J. Clin. Invest. 89:666-672.

7. Thom, S. R. 1990. Carbon monoxide-mediated brain lipid peroxidation in the rat. J. Appl. Physiol. 68:997-1003.

8. Halliwell, B., and J. M. C. Gutteridge. 1989. Protection against oxidants in biological systems: The superoxide theory of oxygen toxicity. In Free Radicals in Biology and Medicine 2nd ed. B. Halliwall and J. M. C. Gutteridge, editors. Clarendon Press, Oxford. 86-187.

9. Floyd, R. A. 1990. Role of oxygen free radicals in carcinogenesis and brain ischemia. FASEB (Fed. Am. Soc. Exp. Biol.) J. 4:2587-2597.

10. Yokoyama, Y., J. S. Beckman, T. K. Beckman, J. K. Wheat, T. G. Cash B. A. Freeman, and D. A. Parks. 1990. Circulating xanthine oxidase: Potential mediator of ischemic injury. Am. J. Physiol. 258:G564-G570.

11. Halliwell, B., and J. M. C. Gutteridge. 1990. Role of free radicals and catalytic metal ions in human disease: An overview. Methods Enzymol. 186:185.

2. Hyslop, P. A., D. B. Hinshaw, W. A. Halsey, Jr., I. Schraufstatter, R. D. Sauerheber, R. G. Spragg, J. H. Jackson, and C. G. Cochrane. 1989. Mechanisms of oxidant-mediated cell injury. J. Biol. Chem. 263:1665-1675.

13. Davies, K. J., M. E. Delsignore, and S. W. Lin. 1987. Protein damage and degradation by oxygen radicals. J. Biol. Chem. 262:9902-9907.

14. Fridovich, I. 1989. Superoxide dismutases: an adaption to a paramagnetic gas. J. Biol. Chem. 264:7761-7764.

15. Turrens, J. F., B. A. Freeman, J. G. Levitt, and J. D. Crapo. 1982. The effect of hyperoxia on superoxide production by lung submitochondrial particles. Arch. Biochem. Biophys. 217:401-410.

16. Piantadosi, C. A., and L. G. Tatro. 1990. Regional $\mathrm{H}_{2} \mathrm{O}_{2}$ concentration in rat brain after hyperoxic convulsions. J. Appl. Physiol. 69:1761-1766.

17. Zhang, J., and C. A. Piantadosi. 1991. Prevention of $\mathrm{H}_{2} \mathrm{O}_{2}$ generation by monoamine oxidase protects against $\mathrm{CNS} \mathrm{O}_{2}$ toxicity. J. Appl. Physiol. 71:10571061.

18. Del Rio, L. A., M. G. Ortega, A. L. Lopez, and J. L. Gorge. 1977. A more sensitive modification of the catalase assay with the Clark oxygen electrode. Application to the kinetic study of the pealeaf enzyme. Anal. Biochem. 80:409-415.

19. Labarca, C., and K. Paigen. 1980. A simple, rapid, and sensitive DNA assay procedure. Anal. Biochem. 102:344-352.

20. Yusa, T., J. S. Beckman, J. D. Crapo, and B. A. Freeman. 1987. Hyperoxia increases $\mathrm{H}_{2} \mathrm{O}_{2}$ production by brain in vivo. J. Appl. Physiol. 63:353-358.
21. Clark, J. B., and W. J. Nicklas. 1970. The metabolism of rat brain mitochondria. J. Biol. Chem. 245:4724-4731.

22. Lai, J. C. K., and J. B. Clark. 1989. Isolation and characterization of synaptic and nonsynaptic mitochondria from mammalian brain. In Neuromethods 11. Carbohydrates and Energy Metabolism. A. A. Boulton, G. B. Baker, and R. F. Butterworth, editors. Humana Press Inc., Clifton, NJ. 43-98.

23. Sakai, Y., A. Tanaka, I. Ikai, Y. Yamaoka, K. Ozawa, and Y. Orii. 1988. Measurement of cytochrome $\mathrm{c}$ oxidase activity in human liver specimens obtained by needle biopsy. Clin. Chim. Acta. 176:343-346.

24. Gornall, A. G., C. J. Bardawill, and M. M. David. 1948. Determination of serum proteins by means of the biuret reaction. J. Biol. Chem. 177:751-766.

25. Anderson, M. E. 1985. Determination of glutathione and glutathione disulfide in biological samples. Methods Enzymol. 113:548-555.

26. Jaeschke, H., and J. R. Mitchell. 1990. Use of isolated perfused organs in hypoxia and ischemia/reperfusion oxidant stress. Methods Enzymol. 186:752759.

27. Floyd, R. A., R. Henderson, J. J. Watson, and P. K. Wong. 1985. Use of salicylate with high pressure liquid chromatography and electrochemical detection (LCED) as a sensitive measure of hydroxyl free radicals in adriamycin treated rats. J. Free Radicals Biol. \& Med. 2:13-18.

28. Halliwell, B., H. Kaur, and M. Ingelman-Sundberg. 1991. Hydroxylation of salicylate as an assay for hydroxyl radicals: A cautionary note. Free Radic. Biol. \& Med. 10:439-441.

29. Powell, S. R., and D. Hall. 1990. Use of salicylate as a probe for $\mathrm{OH}^{\circ}$ formation in isolated ischemic rat hearts. Free Radical Biol. Med. 9:133-141.

30. Olafsdottir, K., and D. J. Reed. 1988. Retention of oxidized glutathione by isolated rat liver mitochondria during hydroperoxide treatment. Biochim. Biophys. Acta. 964:377-382.

31. Reed, D. J., and K. Olafsdottir. 1989. The role of glutathione in mitochondria. In Glutathione Centennial. Molecular Perspectives and Clinical Implications. N. Taniguchi, T. Higashi, Y. Sakamoto, and A. Meister, editors. Academic Press, Inc., San Diego, CA. 35-55.

32. Grootveld, M., and B. Halliwell. 1986. Aromatic hydroxylation as a potential measure of hydroxyl-radical formation in vivo. Identification of hydroxylated derivatives of salicylate in human body fluids. Biochem. J. 237:499-504

33. Sasame, H. A., M. M. Ames, and S. D. Nelson. 1977. Cytochrome P-450 and NADPH cytochrome $\mathrm{c}$ reductase in rat brain. Formation of catechols and reactive catechol metabolites. Biochem. Biophys. Res. Commun. 78:919-926.

34. Turrens, J. F., and J. M. McCord. 1990. Free radical production by the mitochondrion. In Free Radicals, Lipoproteins, and Membrane Lipids. A. Craster de Paulet, et al., editors. Plenum Publishing Corp., New York. 65-71.

35. Zorn, H. 1972. The partial oxygen pressure in the brain and liver at subtoxic concentrations of carbon monoxide. Staub Reinhalt, Luft. 32:24-29.

36. Thompson, J., and M. L. Hess. 1986. The oxygen free radical system: a fundamental mechanism in the production of myocardial necrosis. Prog. Cardiovasc. Dis. 28:449-462. 